\title{
Schwann Cell to Axon Transfer of Ribosomes: Toward a Novel Understanding of the Role of Glia in the Nervous System
}

\author{
Felipe A. Court, ${ }^{1}$ William T. J. Hendriks, ${ }^{2,3}$ Harold D. MacGillavry, ${ }^{3}$ Jaime Alvarez, ${ }^{1}$ and Jan van Minnen ${ }^{3,4}$ \\ ${ }^{1}$ Departamento de Fisiología, Facultad de Ciencias Biológicas, Pontificia Universidad Católica, 114-D Santiago, Chile, ${ }^{2}$ Laboratory for Neuroregeneration, \\ Netherlands Institute for Neuroscience, an Institute of the Royal Academy of Arts and Sciences, 1105 BA, Amsterdam, the Netherlands, ${ }^{3}$ Department of \\ Molecular and Cellular Neurobiology, Center for Neurogenomics and Cognitive Research, Faculty of Earth and Life Sciences, VU University, 1081 HV, \\ Amsterdam, the Netherlands, and ${ }^{4}$ Department of Cell Biology and Anatomy, Hotchkiss Brain Institute, Faculty of Medicine, University of Calgary, Calgary, \\ Alberta, Canada T2N 4N1
}

Schwann cells play pivotal roles in the development and maintenance of the peripheral nervous system. Here, we show that intact sciatic nerve axons of mice contain a small population of ribosomes, which increases by several orders of magnitude when axons are desomatized (severed from their cell bodies). We furthermore demonstrate, using the Wallerian degeneration slow mouse as a model, that Schwann cells transfer polyribosomes to desomatized axons. These data indicate that Schwann cells have the propensity to control axonal protein synthesis by supplying ribosomes on local basis.

Key words: Schwann cell; ribosomes; Wallerian degeneration; axons; glia; intercellular transport

\section{Introduction}

Schwann cells, the glia of the peripheral nervous system (PNS), play several pivotal roles in the development and maintenance of the PNS. In addition to forming the myelin sheath, Schwann cells are involved in neuronal survival where they also provide support to axons during development and throughout adulthood. For example, Schwann cells regulate the caliber and microtubules of axons (Windebank et al., 1985; Hernandez et al., 1989; Bustos et al., 1991), orchestrate the formation and maintenance of the nodes of Ranvier, provide trophic support to the axon after injury and during regeneration (Fields and Stevens-Graham, 2002), and in mature fibers, the differentiated Schwann cells impair the outgrowth and ingrowth of axons (Court and Alvarez, 2000, 2005).

The ability of Schwann cells to regulate axons and their functions relies on reciprocal communications (Stevens and Fields, 2000). Recently, in the field of neuron-glia interaction, a novel concept is emerging. Specifically, Schwann cells have been proposed to supply ribosomes and mRNA to desomatized axons of the Wallerian degeneration slow (Wld ${ }^{s}$ ) mice (Alvarez, 2001).

Received May 23, 2008; revised Aug. 5, 2008; accepted Sept. 10, 2008.

This work was supported by Fondecyt $(1980973,1070377)$, Chile; J.v.M. and W.T.J.H. were supported by a European Union STREP Grant (12702). We thank Joost Verhaagen and Ruben Eggers for help with the Lentivirus experiments; Angelo Quattrini for EM expertise; Mónica Pérez, Gloria Méndez, Adrian Thomson, Yvonne Gouwenberg, and Jean Kawasoe for technical assistance; and Guus Smit, Naweed Syed, and Lawrence Wrabetz for critical discussion.

Correspondence should be addressed to either of the following: Felipe A. Court, Departamento de Fisiología, Facultad de Ciencias Biológicas, Pontificia Universidad Católica, 114-D Santiago, Chile, E-mail: fcourt@bio.puc.dl; or Jan van Minnen, Department of Cell Biology and Anatomy, Hotchkiss Brain Institute, Faculty of Medicine, University of Calgary, Calgary, Alberta, Canada T2N 4N1, E-mail: jvanminn@ucalgary.ca.

DOI:10.1523/JNEUROSCI.2429-08.2008

Copyright $\odot 2008$ Society for Neuroscience ～0270-6474/08/2811024-06\$15.00/0
Along the same line, Eyman et al. (2007) proposed that mRNAs transcribed in squid glial cells are transferred to, and translated in, the axoplasm. Together, these data suggest that the axon receives on a local basis transcripts and components of the machinery for protein synthesis, an unsuspected form of neuron-glia interaction. However, unequivocal evidence for the existence of such interaction is yet to be obtained.

Here, we provide evidence that Schwann cells transfer polyribosomes to the axoplasm. For this, we tagged Schwann cell ribosomes with enhanced green fluorescent protein (eGFP) and showed that tagged ribosomes were translocated to desomatized axons.

\section{Materials and Methods}

Animals. Mice of the C57BL/6J/Wld strain were supplied by Biosonda or Harlan, and wild-type (C57BL/6J) mice were supplied by the local animal house (Facultad de Ciencias Biológicas, Santiago, Chile). Animal care and surgical procedures complied with National Institutes of Health guidelines. Mice weighing $\sim 20$ g were anesthetized with Nembutal $(36 \mathrm{mg} / \mathrm{kg})$ or xylasine-ketamine (6.7-66.7 mg/kg, respectively). The nerve was crushed at the sciatic notch or at midthigh with fine forceps. The crush site was marked with surgical 10-0 nylon monofilament (Ethicon). If applicable, 1-2 $\mu$ l lentivirus in PBS containing $0.1 \%$ fast green was injected into the distal segment of a previously crushed sciatic nerve. In some animals, sciatic nerves were transected at the sciatic notch in addition.

Electron microscopy. Sciatic nerves were processed and sectioned for electron microscopy as described previously (Court and Alvarez, 2000).

Immunocytochemistry. Teased fibers were blocked/permeabilized in PBS containing 5\% fish skin gelatin (Sigma) and 0.2\% Triton X-100 for $1 \mathrm{~h}$ at room temperature and incubated overnight in the same solution with the following primary antibodies: human anti-ribosome antiserum, 1:1000 [from a patient carrying a systemic lupus erythematosus characterized by Massardo et al. (2002), a kind gift from S. Jacobelli, Pontificia Universidad Católica, Santiago, Chile]; mouse anti-neurofilament (clone N52; 

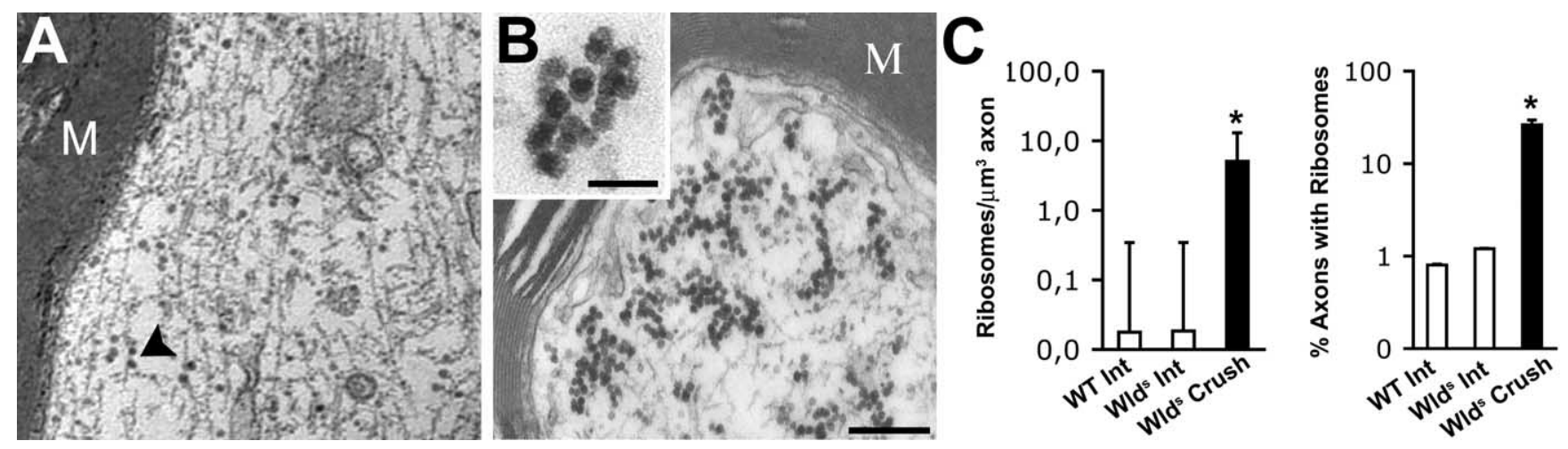

Figure 1. Ribosomes and polyribosomes in axons. $\boldsymbol{A}, \boldsymbol{B}, \operatorname{Intact}(\boldsymbol{A})$ and $W / d^{5}(\boldsymbol{B})$ desomatized for $7 \mathrm{~d}$. $\boldsymbol{A}$, Ribosomes are scarce (arrowhead). $\boldsymbol{B}, A$ field of polyribosomes stands out in the axoplasm, which has not degenerated despite its protracted disconnection from the cell body. Inset, High magnification of an axonal polyribosome. M, Myelin. Scale bars: $200 \mathrm{~nm}$; inset, $50 \mathrm{~nm}$. C, Quantification of ribosomes in wild-type intact (WT int), WId ${ }^{s}$ intact (WId ${ }^{s}$ int) axons, and in desomatized WId ${ }^{s}$ axons crushed $7 \mathrm{~d}$ before (WId ${ }^{\mathrm{s}}$ Crush). Ordinates: scale is logarithmic. Notice the impressive increase in ribosomal content, both in ribosomes per volume of axoplasm $\left({ }^{*} p<0.03\right)$, as well as the number of axons containing ribosomes. $\left({ }^{*} p<0.01\right)$. Student's $t$ test.

Sigma), 1:1000; rabbit anti-S100 (Dako), 1:200; rabbit anti-peripheral myelin glycoprotein P0 (a kind gift from J. P. Brockes, Ludwig Institute for Cancer Research, London, UK), 1:600; rabbit anti-myelin basic protein (MBP; Stem Cell Technologies), 1:200; rabbit anti-GFP (AbCam ab290), 1:500; and human anti-ribosomal P antigen (ImmunoVision), 1:100. After washing, the preparations were incubated for $2.5 \mathrm{~h}$ at room temperature with the appropriate secondary antisera; FITC-donkey anti-mouse IgG1, 1:200; TRITC-goat anti-human IgG, 1:200 (both from Jackson ImmunoResearch); AlexaFluor 647-goat anti-rabbit IgG, 1:400; AlexaFluor 647-goat anti-mouse IgG1, 1:400 (both from Molecular Probes), washed three times in PBS, mounted in Vectashield (Vector Laboratories) and viewed with a Bio-Rad radiance 2000 confocal microscope.

Quantitative immunocytochemistry. From five $(p<0.01)$ mice and five wild-type mice, sciatic nerves were dissected. The nerves were divided into four equal parts. One part was immediately frozen and stored at $-80^{\circ} \mathrm{C}$. The other three parts were transferred to culture medium (see above). At 18, 24, and $48 \mathrm{~h}$, nerves were frozen and stored at $-80^{\circ} \mathrm{C}$. Cryostat sections $(10 \mu \mathrm{m})$ were collected on Superfrost slides, air-dried, and stored at $-80^{\circ} \mathrm{C}$. After thawing, slides were fixed in $4 \%$ paraformaldehyde for $30 \mathrm{~min}$, rinsed in PBS $(3 \times)$, and incubated overnight at $4^{\circ} \mathrm{C}$ with human anti-ribosome antibody, dilution 1:1000 as described above. Next, sections were washed ( $3 \times$ in PBS) and incubated for $1 \mathrm{~h}$ in 1:200 diluted goat anti-human $\operatorname{IgG}$, conjugated to horse-radish peroxidase (Dako). After washing ( $3 \times$ in PBS), the bound antibodies were visualized with $0.01 \%$ diaminobenzidine (Merck). As a control for the immunocytochemical reaction, we used normal human serum. Staining was observed neither in the axoplasm nor in the cytoplasm of resident cells of the nerve (data not shown).

To quantify the immunoreactive axons, only cross-sectioned fibers with a complete myelin sheath were considered. From each nerve, at least 250 fibers were evaluated double blindly. For statistical analysis, the Student's $t$ test was performed to determine statistical differences.

Quantification of ribosomes. Quantification of ribosomal content in axons was performed on intact $W l d^{s}$ and wild-type axons, and in $W l d^{s}$ axons transected for $7 \mathrm{~d}$ (four nerves for each condition). At the electron microscopical (EM) level, ribosomes were counted in 250 axons randomly chosen in two sections $100 \mu \mathrm{m}$ apart; the thickness of EM sections was $80 \mathrm{~nm}$. To estimate the volume of the axoplasm sampled, axons were assumed to be cylinders. In semithin Epon sections, the diameter of 100 axons randomly chosen was measured with an ocular micrometer. Values are expressed as ribosome $/ \mu \mathrm{m}^{3}$ of axoplasm [(average ribosome/ axon)/(average volume of axoplasm surveyed)].

Ribosome purification. The supernatant of the ribosomal pellet was dialyzed and concentrated. The ribosomal pellet (see Fig. $2 \mathrm{~A}$, inset) was resuspended in sample buffer. Twenty micrograms of each sample was loaded on a $10 \%$ acrylamide gel. As a control, histidine-eGFP $(20 \mu \mathrm{g})$ was loaded also. After blotting, the PDVF membrane was incubated with rabbit anti-GFP $(1: 10,000)$ followed by anti-rabbit $\operatorname{HRP}(1: 10,000)$, and immunoreactive bands were visualized with an ECL kit.

Lentivirus production. For ribosomal labeling, an lentiviral (LV) vector was constructed containing a fusion reporter gene comprising the ribosomal protein L4 and eGFP. For construction of the fusion protein L4-eGFP, the L4 fragment was amplified with PCR from a rat cDNA library with the following primers: forward primer $\left(5^{\prime}\right)$ containing an NheI restriction site: AAG-CTAGCC-CGC-CAC-CAT-GGC-TTG-TGC-CCG-TCC-CC; reverse primer $\left(3^{\prime}\right)$ containing a Sall site: GAG-TCG-ACT-GCA-GCA-GAC-TTT-TTTTCT-TCT-G. The L4 fragment was subsequently cloned into the multiple cloning site (MCS) of pEGFP-N2 (BD Biosciences; Clontech) between NheI $\left(5^{\prime}\right)$ and SALI (3'). The L4-eGFP fragment was then cut from pL4-eGFP-N2 with NheI $\left(5^{\prime}\right)$ and $\mathrm{XbaI}\left(3^{\prime}\right)$ and cloned into the MCS at the XbaI restriction site of the LV vector p156RRLsin-PPThCMVMCS-eGFP-wpre (kindly provided by Dr. L. Naldini, San Raffaele Institute, Milan, Italy). This LV vector contains a cytomegalovirus (CMV) promoter along with the HIV-1-Sin 18 LTR and the HIV-1 genomic RNA packaging signal, a Rev response element (RRE), a central polypurine tract (PPT), the human CMV promoter (hCMV) followed by the fusion construct L4-eGFP and the woodchuck posttranscriptional regulatory element (WPRE), flanked by two longterminal repeats (LTRs). The LV fusion construct was finally sequenced to verify its insert and checked for right orientation. To produce viral vectors, the LV-L4-eGFP or the LV-eGFP (Blömer et al., 1997) transfer plasmids were co-transfected with the viral core packaging construct pCMVdeltaR8.74 and the VSV-G envelope protein vector pMD.G.2 into 293T cells as previously described (Naldini et al., 1996b). Briefly, $5 \times 10^{6} 293 \mathrm{~T}$ cells were seeded in $10 \mathrm{~cm}$ dishes $24 \mathrm{~h}$ before transfection in complete Iscove's Modified Dulbecco's Medium (IMDM) containing 10\% fetal calf serum (FCS), $1 \times$ glutamine (Gln) and $1 \times$ penicillin/streptomycin (PS) and grown in a $5 \% \mathrm{CO}_{2}$ incubator. Two hours before transfection, the culture medium was changed. For each $10 \mathrm{~cm}$ dish, $10 \mu \mathrm{g}$ of transfer vector plasmid, $6.5 \mu \mathrm{g}$ of envelope plasmid, and $3.5 \mu \mathrm{g}$ of packaging plasmid were cotransfected using the calcium phosphate method. The medium was replaced with IMDM containing $2 \%$ FCS, $1 \times$ Gln and $1 \times$ PS after $14-16 \mathrm{~h}$, and the $\mathrm{LV}$ particle containing conditioned medium was collected $24 \mathrm{~h}$ later, cleared by low-speed centrifugation ( $176 \mathrm{~g}$ for $5 \mathrm{~min}$ ) and filtered through a $0.22 \mu \mathrm{m}$ cellulose acetate filters. The supernatant was concentrated $\sim 100$-fold by ultra centrifugation $(53,000 \mathrm{~g}$ for $2.5 \mathrm{~h})$. The pellet was resuspended in PBS and aliquots of LV-L4-eGFP stored at $-80^{\circ} \mathrm{C}$. The titer (transducing units $/ \mathrm{ml} ; \mathrm{TU} / \mathrm{ml}$ ) was determined by transducing $293 \mathrm{~T}$ cells with serial dilutions of the LV-L4eGFP vector in complete IMDM. Transduced cells were incubated for $24 \mathrm{~h}$ and thereafter medium was replaced with fresh IMDM and cells were incubated for another $24 \mathrm{~h}$. The titer was determined by counting GFP positive cells under a fluorescence microscope and was $1.5 \times 10^{9} \mathrm{TU} / \mathrm{ml}$.

\section{Results}

Axonal desomatization increases content of axonal ribosomes Desomatized axons of $W l d^{s}$ mice survive for several weeks (Lunn et al., 1989). Our previous study on $W l d^{s}$ mice demonstrated that desomatized axons contain many ribosomes compared with their intact axon counterparts (Court and Alvarez, 2005). To follow up 
this finding, we studied ribosomes of axons in three conditions: wild-type intact, $W l d^{s}$ intact, and $W l d^{s}$ desomatized for $7 \mathrm{~d}$. In intact axons of wild-type or $W l d^{s}$ mice, ribosomes, mostly in the form of single ribosomes, were scarce (Fig. $1 A$ ). In desomatized $W l d^{s}$ axons, a dramatic increase occurred and ribosomes were often arranged in polysomal clusters (Fig. $1 B$ ). These polyribosomes were embedded in the neurofilament space and also packed in multimembrane vesicles [ribosome-containing vesicles (RVs)] (Fig. 3C). To quantify the magnitude of this phenomenon, in this study we determined the number of polyribosomes in the cytosol. In intact axons of wild-type and $W l d^{s}$ mice, the average number of polyribosomes per volume of axoplasm was $\sim 0.02 / \mu \mathrm{m}^{3}$, whereas during desomatization of $W l d^{s}$ axons, ribosomes increased by two orders of magnitude. The fraction of axons that exhibited ribosomes in a cross-section of the nerve ( $\sim 1 \%$ in intact axons) increased by one order of magnitude during desomatization (Fig. 1C). In desomatized axons of wild-type mice, before their degeneration, ribosomes also increased. For this, nerve explants of $W l d^{s}$ and wild-type mice were kept in vitro for $18-48 \mathrm{~h}$. At time $0, \sim 4 \%$ of axons showed anti-ribosome immunoreactivity. At $18 \mathrm{~h}, \sim 15 \%$ were positive, whereas up to $48 \mathrm{~h}$, there was no significant increase. Values for wild-type and $W l d^{s}$ nerves were similar at all time points (supplemental Fig. 1, available at www. jneurosci.org as supplemental material). Because the nerve explants deteriorate with time, the early arrest of the ribosomal increase may not apply to in vivo severed axons. These results indicate that desomatization triggers a fast increase of axonal ribosomes, as most of it occurs in the first hours and that the increase of ribosomes in axons and the underlying mechanism are phenomena that belong to the species rather than to the $W l d^{s}$ mouse strain.

\section{Schwann cells transfer ribosomes to desomatized axons}

Ribosomal subunits are assembled in the nucleus and exported to the cytoplasm. When the small subunit recruits the initiation complex and binds a mRNA, the large subunit is subsequently bound to form a ribosome (Alberts et al., 2002). In a desomatized axon, the parent cell body cannot supply extra ribosomes to the axoplasm, and the axoplasm is unable to synthesize RNA. Therefore, desomatized axons must receive their ribosomes from an extraneuronal source. Because glial cells were reported to transcribe axonal RNAs in a squid model system (Eyman et al., 2007), we surmised that Schwann cells supply ribosomes to mammalian axons. To test this conjecture, Schwann cell ribosomes were tagged with eGFP. For this, we constructed an LV vector to express the ribosomal protein L4 fused to eGFP (LV-L4-eGFP). Upon infection, the host cell produces DNA strands from the viral RNA, which are integrated into its genome for subsequent transcription and translation (Naldini et al., 1996a). Thus, if the vector is injected into severed nerves and afterward axons exhibit L4-eGFP-tagged ribosomes, they should have originated in infected cells associated with the desomatized axons.

First, to assess whether L4-eGFP fusion protein does incorporate into ribosomes, HEK cells were infected with the lentivirus. Abundant L4-eGFP was recovered in the ribosomal fraction of these cells, whereas it was undetectable in the cytosolic fraction (Fig. 2A).

Next, the sciatic nerve of $W l d^{s}$ mice was crushed at mid-thigh, and LV-L4-eGFP was injected into the nerve distal to the crush; in addition, the nerve was cut at the sciatic notch to introduce a gap of $\sim 2 \mathrm{~mm}$ to insure that axons are indeed severed from their cell bodies. Seven days later, nerves were processed, and cryostat section and teased fibers were investigated with the relevant antisera. In the injected nerve, i.e., distal to the crush, Schwann cells exhibited L4eGFP fluorescence, which colocalized with a specific anti-ribosomal antibody. In axons, the ribosomal staining appeared as diffuse patches and as puncta, in keeping with the EM data, and the L4eGFP fluorescence colocalized with the ribosomal marker (Fig. $2 B$; supplemental Fig. $2 A$, available at www.jneurosci.org as supplemental material). All axons showing the L4-eGFP label were enveloped by labeled Schwann cells. Central to the crush, a zone adjacent to that infiltrated with the viral suspension, neither resident cells of the nerve nor axons showed L4-eGFP signal (supplemental Fig. 3, available at www.jneurosci.org as supplemental material).

To quantify the above data, Schwann cells and their associated axons were scored for the LV-L4-eGFP labeling. A total of 236 axons from three animals were surveyed. In desomatized $W l d^{s}$ axons, 79\% of myelinating Schwann cells exhibited L4-eGFP signal, and $\sim 60 \%$ of axons associated with these cells showed a diffuse and/or punctate L4-eGFP signal in the neurofilament space (compare Fig. $2 B$; supplemental Fig. $2 A$, available at www.jneurosci.org as supplemental material). Conversely, uninfected Schwann cells, i.e., L4-eGFP negative, encompassed L4-eGFP negative axons (supplemental Fig. $2 B$, available at www.jneurosci.org as supplemental material). The L4-eGFP signal largely colocalized with the immunostaining of ribosomes in both Schwann cells and axons (Fig. $2 B$, supplemental Fig. $2 A$, available at www.jneurosci.org as supplemental material): in $84 \%$ of puncta in the axoplasm, signals colocalized. In summary, our data point positively to a Schwann cell-to-axon transfer of ribosomes, whereas the cell body as an alternative supplier has been excluded by desomatization.

We studied next whether ribosomes were transferred selectively, or along with other Schwann cell proteins. For this, we focused on the Schwann cell specific protein S100, which resides in the Schwann cell cytosol (Moore, 1972). In desomatized Wld ${ }^{s}$ fibers, Schwann cells were stained strongly with an antiserum to S100. In axons, S100 was undetectable, whereas ribosomes showed a clear immunostaining (supplemental Fig. 4, available at www.jneurosci.org as supplemental material). As an additional control for unspecific transfer of Schwann cell cytoplasmic components, we used the LV coding for eGFP which, after translation, remains in the cytosol of infected cells (Blömer et al., 1997). The same experimental protocol described above was used to express the LV-eGFP vector in the nerve. The Schwann cell cytoplasm exhibited a strong eGFP fluorescence and anti-ribosome immunofluorescence. In the neurofilament space of the encompassed axon, ribosome immunoreactivity was also detected whereas eGFP fluorescence was absent (Fig. 2C). Together, these data indicate that transcellular transfer of ribosomes is selective, as at least the two cytosolic proteins we investigated were excluded from transfer.

\section{Intercellular route of Schwann cell to axon transfer of ribosomes}

To investigate how Schwann cell-derived ribosomes gain access to the axoplasm, we applied confocal microscopy and electron microscopy. Immunofluorescence revealed that protrusions of Schwann cells carrying anti-ribosome signal occasionally invaginated into the axon both in internodes (Fig. $3 A$ ) and paranodes (supplemental Fig. 5, available at www.jneurosci.org as supplemental material). In close vicinity to these invaginations, in the axoplasm, anti-ribosome positive puncta were detected. Some of these puncta showed complete or partial colocalization of antiribosome and anti-MBP immunoreactivity (supplemental Fig. $6 A-C$, available at www.jneurosci.org as supplemental material), which suggests that these puncta were former Schwann cell invaginations that during detachment became part of the axoplasm. The partial colocalization may be indicative of the release of ribosomes from the puncta into the axoplasm (supplemental 


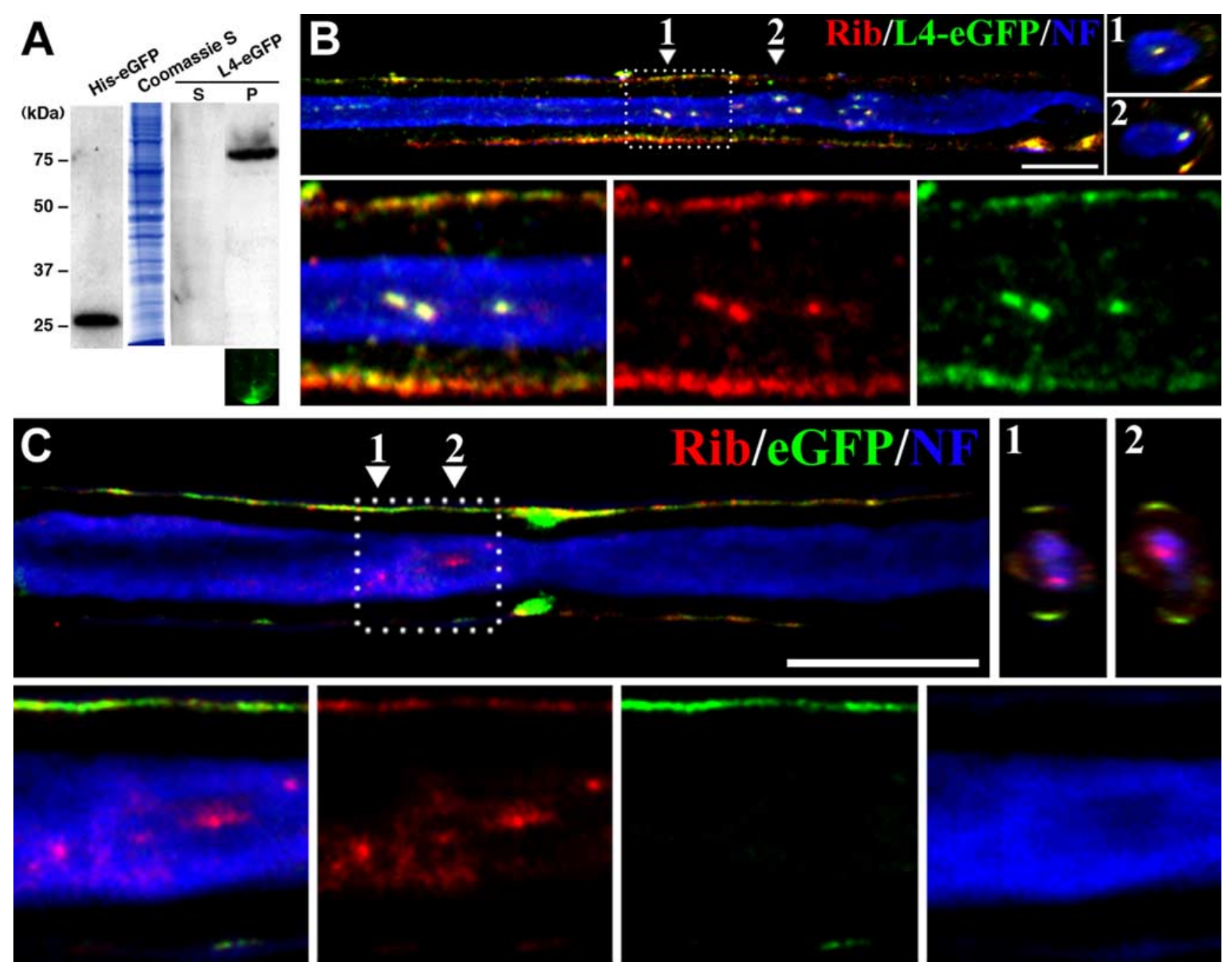

Figure 2. Transfer of ribosomes from Schwann cell to axon. $\boldsymbol{A}$, Western blot showing incorporation of the L4-eGFP fusion protein into ribosomes. HEK cells were infected with LV-L4-eGFP, fractionated, after which the blot was stained with anti-eGFP. First lane, Histidine-tagged eGFP; second lane, coomassie-stained supernatant of pellet fraction; third lane, supernatant of pellet fraction; fourth lane, sucrose gradient of purified ribosomal fraction. The antibody recognizes a single band that corresponds to the molecular weight of His-eGFP (first lane) and the fusion protein (fourth lane), respectively. In the supernatant (third lane), no signal is detected, indicating that the cytosol contains little if any L4-eGFP. Bottom image, The ribosomal pellet shows intense eGFP fluorescence after sucrose gradient purification. $\boldsymbol{B}, \boldsymbol{C}$, WId ${ }^{5}$ teased fibers, $7 \mathrm{~d}$ after crush; the distal segment of the nerve was injected immediately after the crush with LV-L4-eGFP $(\boldsymbol{B})$, or with LV-eGFP ( $($ ). Color codes indicate the antibodies used. $\boldsymbol{B}$, Top, Triple immunostaining and Z-projections at the corresponding numbers; in the neurofilament space, puncta are seen in which ribosomal and L4-EGFP fluorescent markers colocalize. Bottom, Higher magnification of boxed area shows in detail colocalization of signals in both Schwann cell cytoplasm and axoplasm (merged signals, left), ribosome signal (middle), and L4-eGFP signal (right). $\boldsymbol{C}$, as in B, except that the encoded protein lacked the ribosomal protein L4. Ribosomal signals are present in Schwann cells and axoplasm, but eGFP is present only in the Schwann cell. These results suggest that the transfer mechanism between Schwann cells and axons is selective. Scale bars, $10 \mu \mathrm{m}$.

Fig. 6C, available at www.jneurosci.org as supplemental material) (see also Fig. 3D; supplemental Fig. $7 E-H$, available at www. jneurosci.org as supplemental material). In intact nerves, antiribosome positive puncta could also be observed, although they were detected much less frequently (supplemental Fig. $8 \mathrm{~A}$, available at www.jneurosci.org as supplemental material).

At the EM level, in $7 \mathrm{~d}$ desomatized $W l d^{s}$ axons, we identified polyribosomes in one to several enlarged layers of adaxonal Schwann cell cytoplasm and also in cytoplasmic protrusions of Schwann cell into the axoplasm (Fig. $3 B$ ). In addition, we observed polyribosomes in vesicles surrounded by two or multiple membranes, giving rise to RVs. The morphology of these structures can be quite complex with ribosomes present between multiple layers of the Schwann cell membranes (Fig. 3C; supplemental Fig. 7, available at www.jneurosci.org as supplemental material). From some of these RVs the outer membrane was discontinuous, creating a continuum between the content of the vesicles and the axoplasm (Fig. 3D; supplemental Fig. $7 E-H$, available at www.jneurosci.org as supplemental material). Combining the LM and EM data we propose the pathway depicted in Figure 4 for the transit of ribosomes from the outer cytoplasm of the Schwann cell to the axoplasm.

In intact axons, in addition to ribosomes (see above) also RVs were occasionally detected. (supplemental Fig. $8 B$, available at www.jneurosci.org as supplemental material), suggesting that in intact axons ribosomes may also be derived from glial cells.

\section{Discussion}

We here demonstrate that mature axons harbor a small population of ribosomes, confirming and extending the report of Koenig et al. (2000), and in addition, we show that their numbers increase dramatically on desomatization of axons. Moreover, using the $W l d^{s}$ mouse as a model, our data point to a novel notion 

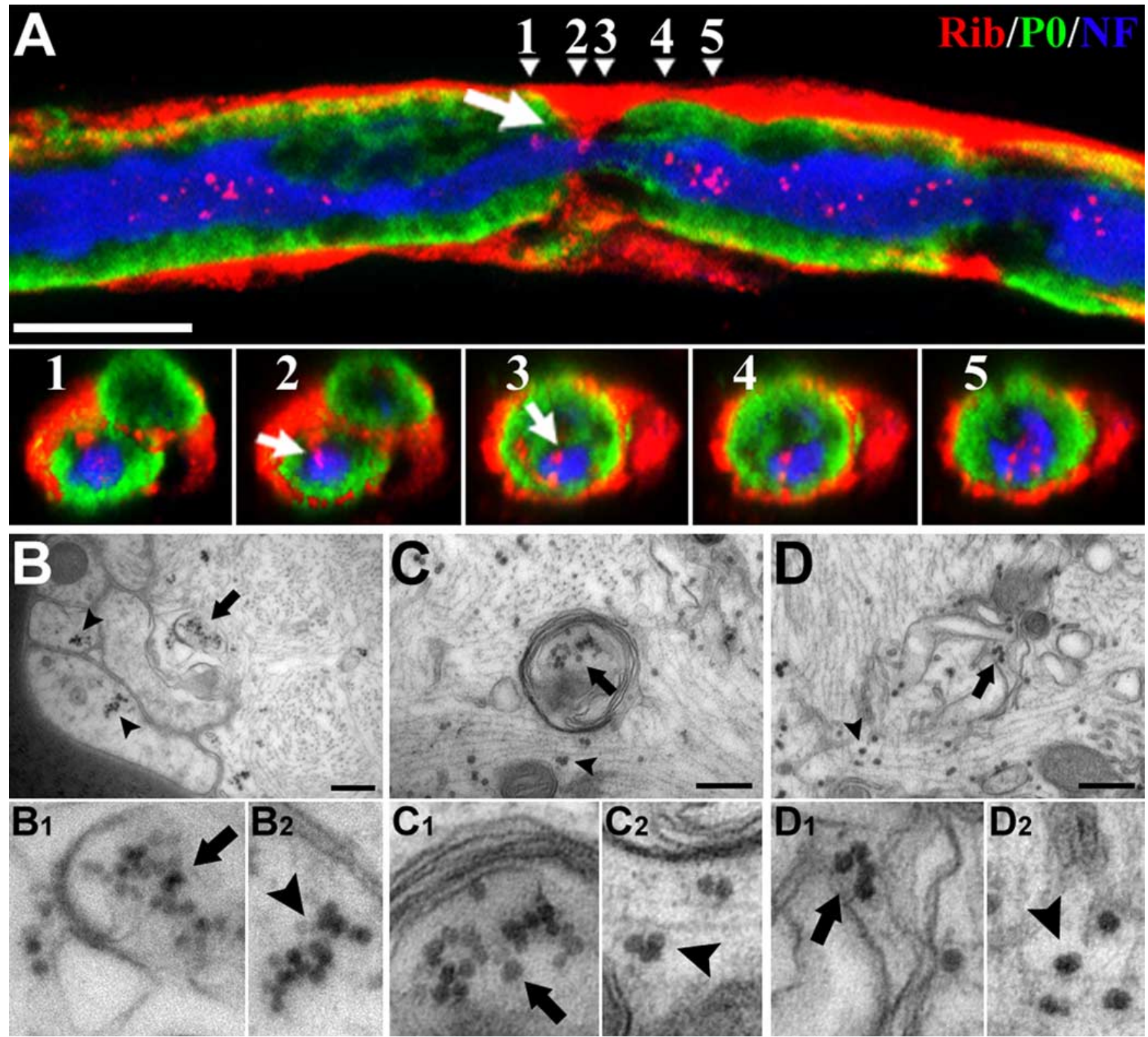

Figure 3. Putative intercellular pathway of ribosomal transfer. WId ${ }^{s}$ axons desomatized $7 \mathrm{~d}$ before. $A$, Teased fiber: triple immunostaining using anti-ribosome, neurofilament, and P0 antisera. Top, Ribosome immunoreactive puncta are clearly seen in the axoplasmic space outlined by the neurofilament staining; the arrow points to a structure penetrating through the myelin marked by the P0 staining, akin to a Schmidt-Lanterman incisure; bottom, Z-projections of the corresponding numbers of the top show ribosomal signal from the Schwann cell penetrating into the axoplasm (arrows in 2 and 3). Scale bar, $10 \mu \mathrm{m} . \boldsymbol{B}-\boldsymbol{D}$, EM micrographs of WId ${ }^{5}$ axons desomatized for $7 \mathrm{~d}$. B, Polyribosomes (arrowheads) can be seen in enlarged adaxonal pockets of $S c h w a n n$ cell cytoplasm. At the arrow, a Schwann cell protrusion loaded with ribosomes appears to be in the process of disengaging itself from the Schwann cell. $\boldsymbol{C}$, Vesicle with multiple membranes contains several polyribosomes (arrow), whereas many polyribosomes are present in the axoplasm (arrowhead). D, Vesicle with ruptured membranes, creating a continuum between the vesicular space and axoplasm [note a polyribosome at the interface between vesicle and axoplasm (arrow) and polyribosomes in the axoplasm (arrowheads)]. Scale bars, $300 \mathrm{~nm}$. B1-D2 are high magnification images of areas indicated by arrows and arrowheads in $\boldsymbol{B}-\boldsymbol{D}$. Together, these images suggest the pathway followed by ribosomes from the Schwann cell to the axoplasm.

in the relationship between Schwann cells and axons in that polyribosomes in desomatized axons originate in the Schwann cell. However, we cannot exclude the possibility that mRNA encoding the L4-eGFP fusion protein is also transferred from Schwann cells, translated in the axon and added to partially assembled ribosomes or exchanged with L4-protein on preexisting ribosomes. This latter possibility was suggested for synaptically translated Aplysia ribosomal proteins (Moccia et al., 2003). Furthermore, our data do not exclude the neuronal cell body as another supplier of axonal ribosomes in intact axons.

The transfer of polyribosomes between two cell types of the nervous system is surprising and unsuspected. Because polyribo- somes consist of several ribosomes translating simultaneously a strand of mRNA (Alberts et al., 2002), our data imply that Schwann cells have the ability to transfer mRNA as well. This creates the possibility for Schwann cells to modify the repertoire of gene expression and protein production of the recipient axon.

Several authors have raised the possibility that glial cells modulate gene expression in axons. For instance, Li et al. (2005) suggested in an EM study that CNS glia transfers ribosomes to spinal cord axons. In this study, they showed the presence of double-walled vesicles at the axonal-myelin sheath interface, which often contained ribosome-like particles (Li et al., 2005). More recently, Eyman et al. (2007) proposed, for a squid nerve fiber model, that glial cells tran- 


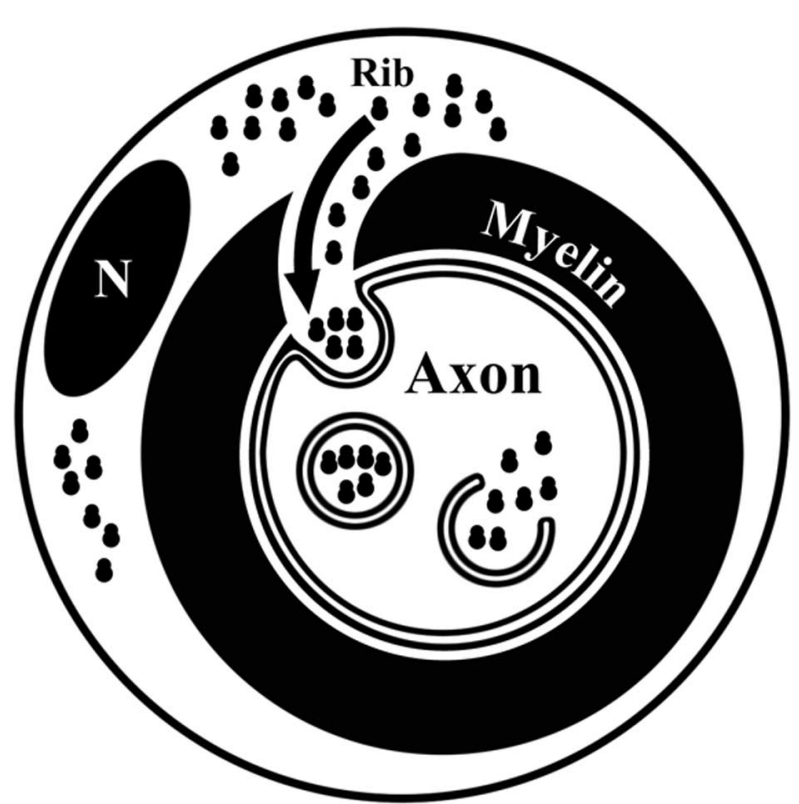

Figure 4. Proposed trajectory of ribosomes moving from the outer Schwann cell cytoplasm into the axoplasm. Ribosomes (Rib) move from the periaxonal Schwann cell cytoplasm through cytoplasmic channels that serve to supply the adaxonal Schwann cell cytoplasm. Here, ribosomes accumulate and protrusions of the Schwann cell cytoplasm invaginate into the axon and, during detachment from the Schwann cell, give rise to RVs. After rupture of RVs, the ribosomes gain access to the axoplasm. N, Schwann cell nuclei.

scribe RNAs to be translated in the axoplasm. Also for other cell associations, intercellular transfer of RNA and organelles has been reported previously. For instance, Drosophila follicle cells supply mRNA to oocytes (Palacios, 2002), and mast cells transfer mRNAs and micro-RNAs between them (Valadi et al., 2007). Examples of transcellular transfer of organelles include melanosomes, that are transferred from melanocytes to keratinocytes (Boissy, 2003), and mitochondria in a lung epithelial cell line (Spees et al., 2006). Furthermore, PC12 cells exchange vesicles and organelles (Rustom et al., 2004). Together, these data indicate that the transfer of organelles and RNA may be a widespread mechanism by which the donor cells can regulate the physiology of the recipient cells. The transfer of polyribosomes between Schwann cells and axons described here is likely to be an adaptation of the nervous system of this intercellular transfer mechanism.

How do Schwann cell polyribosomes gain access to the axoplasm? In desomatized axons, our electron microscopical and immunofluorescent data point to the following sequence of events. First, polyribosomes accumulate in the adaxonal Schwann cell cytoplasm; then this part of cytoplasm enclosed in membranes protrudes into the axon, and finally it detaches from the Schwann cell. The resulting vesicles (RVs) have at least two sets of membranes, the outermost is of axonal origin, whereas the (multiple) subsequent membranes are of Schwann cell origin. Once inside the axon, the membranes of the RVs rupture through an unknown mechanism, and the content of the RVs, including the polyribosomes, has access to the axoplasm. Our data indicate that RVs are loaded selectively in the Schwann cell cytoplasm, as S100 and (overexpressed) eGFP are not detected in RVs or axoplasm. Furthermore, also cellular organelles appear to be selectively sorted into the RVs as we never detected organelles other than ribosomes (e.g., mitochondria) in the RVs.

In conclusion, the transfer of ribosomes and mRNA from Schwann cells to axons shown here point at a novel concept, namely, that the phenotype of axons can be controlled on a local basis and relies on genetic programs of the associated glial cells. We anticipate that this notion will suggest new avenues of research in the organization of the nervous system as well as neuropathology.

\section{References}

Alberts B, Johnson A, Lewis J, Raff M, Roberts K, Walter P (2002) Molecular biology of the cell, Ed 4. New York: Garland Science.

Alvarez J (2001) The autonomous axon: a model based on local synthesis of proteins. Biol Res 34:103-109.

Blömer U, Naldini L, Kafri T, Trono D, Verma IM, Gage FH (1997) Highly efficient and sustained gene transfer in adult neurons with a lentivirus vector. J Virol 71:6641-6649.

Boissy RE (2003) Melanosome transfer to and translocation in the keratinocyte. Exp Dermatol 12 [Suppl 2]:5-12.

Bustos J, Vial JD, Faúndez V, Alvarez J (1991) Axons sprout and microtubules Increase after local Inhibition of RNA synthesis, and microtubules decrease after inhibition of protein synthesis: A morphometric study of rat sural nerves. Eur J Neurosci 3:1123-1133.

Court F, Alvarez J (2000) Nerve regeneration in Wld(s) mice is normalized by actinomycin D. Brain Res 867:1-8.

Court FA, Alvarez J (2005) Local regulation of the axonal phenotype, a case of merotrophism. Biol Res 38:365-374.

Eyman M, Cefaliello C, Ferrara E, De Stefano R, Lavina ZS, Crispino M, Squillace A, van Minnen J, Kaplan BB, Giuditta A (2007) Local synthesis of axonal and presynaptic RNA in squid model systems. Eur J Neurosci 25:341-350.

Fields RD, Stevens-Graham B (2002) New insights into neuron-glia communication. Science 298:556-562.

Hernández C, Blackburn E, Alvarez J (1989) Calibre and microtubule content of the non-medullated and myelinated domains of optic nerve axons of rats. Eur J Neurosci 1:654-658.

Koenig E, Martin R, Titmus M, Sotelo-Silveira JR (2000) Cryptic peripheral ribosomal domains distributed intermittently along mammalian myelinated axons. J Neurosci 20:8390-8400.

Li YC, Li YN, Cheng CX, Sakamoto H, Kawate T, Shimada O, Atsumi S (2005) Subsurface cisterna-lined axonal invaginations and double-walled vesicles at the axonal-myelin sheath interface. Neurosci Res 53:298-303.

Lunn ER, Perry VH, Brown MC, Rosen H, Gordon S (1989) Absence of Wallerian degeneration does not hinder regeneration in peripheral nerve. Eur J Neurosci 1:27-33.

Massardo L, Burgos P, Martínez ME, Pérez R, Calvo M, Barros J, González A, Jacobelli S (2002) Antiribosomal P protein antibodies in Chilean SLE patients: no association with renal disease. Lupus 11:379-383.

Moccia R, Chen D, Lyles V, Kapuya E, E Y, Kalachikov S, Spahn CM, Frank J, Kandel ER, Barad M, Martin KC (2003) An unbiased cDNA library prepared from isolated Aplysia sensory neuron processes is enriched for cytoskeletal and translational mRNAs. J Neurosci 23:9409-9417.

Moore BW (1972) Chemistry and biology of two proteins, S-100 and 14.3.2, specific to the nervous system. Int Rev Neurobiol 15:215-225.

Naldini L, Blömer U, Gage FH, Trono D, Verma IM (1996a) Efficient transfer, integration, and sustained long-term expression of the transgene in adult rat brains injected with a lentiviral vector. Proc Natl Acad Sci U S A 93:11382-11388.

Naldini L, Blömer U, Gallay P, Ory D, Mulligan R, Gage FH, Verma IM, Trono D (1996b) In vivo gene delivery and stable transduction of nondividing cells by a lentiviral vector. Science 272:263-267.

Palacios IM (2002) RNA Processing: splicing and the cytoplasmic localisation of mRNA. Curr Biol 12:R50-R52.

Rustom A, Saffrich R, Markovic I, Walther P, Gerdes HH (2004) Nanotubular highways for intercellular organelle transport. Science 303:1007-1010.

Spees JL, Olson SD, Whitney MJ, Prockop DJ (2006) Mitochondrial transfer between cells can rescue aerobic respiration. Proc Natl Acad Sci U S A 103:1283-1288.

Stevens B, Fields RD (2000) Response of Schwann cells to action potentials in development. Science 287:2267-2271.

Valadi H, Ekström K, Bossios A, Sjöstrand M, Lee JJ, Lötvall JO (2007) Exosome-mediated transfer of mRNAs and microRNAs is a novel mechanism of genetic exchange between cells. Nat Cell Biol 9:654-659.

Windebank AJ, Wood P, Bunge RP, Dyck PJ (1985) Myelination determines the caliber of dorsal root ganglion neurons in culture. J Neurosci 5:15631569 . 